\title{
On the Development of China's Natural Gas Industry and the Market-Oriented Reform
}

\author{
Fengyun Wang ${ }^{1, a}$, Xiaofan Liu ${ }^{1, b}$ \\ ${ }^{1}$ International Economics and Trade Department, Economics \& Management School, Beijing \\ Institute of Petrochemical Technology, China, 102617 \\ email: awangfengyun@bipt.edu.cn, ${ }^{b} 1406178741 @ q q . c o m$
}

\begin{abstract}
Keywords: natural gas, supply and demand of natural gas, import of natural gas, dispatching ability, natural gas pricing, market-oriented reform

Abstract. As a kind of environmental, economical and high efficient energy, natural gas has become the first choice for the development and utilization of many countries. In this paper, we analyze the production, consumption, import and export of China's natural gas in recent decades, research the problems of the natural gas sources shortage, the large differences of regional distribution, the poor dispatching ability and the unreasonable pricing. Finally, we put forward countermeasures and suggestions of nature gas industry development about ensuring nature gas supply, developing infrastructure, enhancing the construction of pipe network, and impelling marketable pricing mechanism.
\end{abstract}

\section{Introduction}

Energy is an important material basis for the survival and development of human society. The energy consumption structure can reflect the progress of social civilization and influence significantly the natural environment. The use of energy shows the trend that is from high carbon to low carbon, and realizing carbon free economy in the end. With a large population, China has a low per capita share of energy. Besides, the external dependence degree of oil and gas increases ceaselessly. The energy structure based the coal causes a great pressure on ecological environment. So there are urgent needs for clean and efficient energy, and optimizing the structure of energy consumption ${ }^{[1]}$. As relatively clean, high-quality fossil energy, natural gas has the lowest carbon emission coefficient, complies with the trend of low carbon economy development. In China, it has been developed rapidly, which has been used in every field of life and production.

From a global point of view, the world's remaining proved reserves of natural gas are $198.9 \times 10^{12} \mathrm{~m}^{3}$ in 2013. Compared with 2012, it increased $3.9 \times 10^{12} \mathrm{~m}^{3}$, which is up to $2 \%$ of increase range. From 2009 to 2013, natural gas proved reserves increased by $11.7 \times 10^{12} \mathrm{~m}^{3}$, the global natural gas industry will continue developing rapidly in the future.

Compared with the international level, the development lever of natural gas is still lower, and the base of natural gas industry is relatively weak in China. The proportion of natural gas in China's energy consumption structure was around 3\% in a long time. On December 30, 2004, the official commercial project of the West-East Natural Gas Transmission began to carry out. It marks the China's natural gas market further develop, which is expected to continue developing until 2030. During this period, China's natural gas will be developed rapidly, including the increase of natural gas pipeline construction, the augment of the gas source, and so on. In this case, it will also promote the development of clean energy industry .So natural gas will have a broad development prospects in China.

\section{The situation of China's natural gas development}

In order to study China's natural gas development situation, we will analyze the supply, demand, import and export of China's natural gas. 
The supply of natural gas in China. The resource potential of natural gas is greater than that of oil in China. In 2014, the national output of crude oil and natural gas reached a highest level, while the remaining allowable exploitation of oil and natural gas is respectively 20600 million tons and 3850 million cubic meters. According to 1111 cubic meters of natural gas converted to 1 tons of oil , the remaining allowable exploitation of natural gas is about 1.7 times as much as that of oil. Because natural gas has a certain substitution effect on oil, and the increase of its potential will further guarantee China's energy security. So, China will enter the rapid development stage of natural gas in the future.

The output of natural gas keeps the trend of rapid growth in China. According to figure 1, China's natural gas production increased slowly from 1980 to 1992. With the advance of China's reform and opening-up, China's natural gas production has increased quickly since 1993. In 2013, China's natural gas production is 117.05 billion cubic meters, and year-on-year growth is $8.6 \%$. In 2014, China's natural gas production is 132.9 billion cubic meters, and net increase is 13.2 billion cubic meters, and year-on-year growth is $10.7 \%$. The increase of production will relieve the problem of the shortage of natural gas in China, and has a supportability effect on industry and people's life.
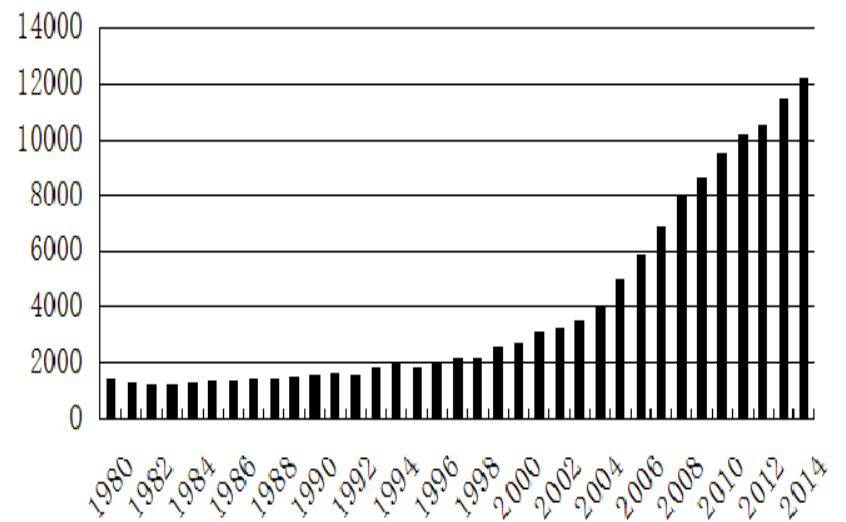

Fig. 1 China’s nature gas supply situation from 1980 to 2014

(unit: 10 thousand cubic meters)
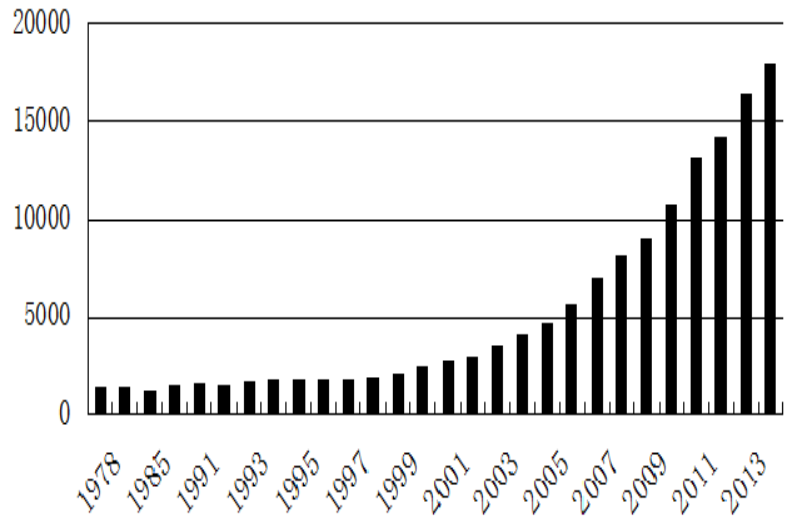

Fig. 2 China’s apparent consumption of natural gas from 1978 to 2014(unit: 10 thousand cubic meters)

Notes: Data from China Statistical Yearbook 2014, 2014 National Economic and Social Development Statistical Bulletin

China's natural gas reserves are rich, but its distribution is nonuniform. In recent years, China's natural gas proved reserves increased significantly. By the end of 2013, the verified natural gas reserves is 4.6 trillion cubic meters, and newly increase 942.62 billion cubic meter in 2014. But proved natural gas resources are mostly located in the Midwest of China. At the same time, China's developed and densely populated areas are mostly concentrated in the eastern coastal areas, in which there is high demand of natural gas, and it is far from the natural gas source areas. While in the western areas, they lack capital and technology of exploit resources, but close to the natural gas source areas. The separation between the place of production and consumption has a serious impact on the rational use and development of natural gas.

Annual natural gas output is rich, but the per capita amount is too low. As shown in the table 1, in 2013, China's nature gas output reached 117.05 billion cubic meters, and ranked in the sixth in the world, which belongs to the high natural gas output country. China has the largest population in the world. So the per capita amount of natural gas is only 87.48 cubic meters, and is far below the world average level 488.74 cubic meters. 
Table 1 Top 10 countries of natural gas production per capita holding amount

\begin{tabular}{ccccc}
\hline rank & nation & $\begin{array}{c}\text { Annual natural } \\
\text { gas output } \\
\text { (billion cubic } \\
\text { meters) }\end{array}$ & $\begin{array}{c}\text { population(100 } \\
\text { million people) }\end{array}$ & $\begin{array}{c}\text { per capita } \\
\text { amount of gas } \\
\text { (cubic meters) }\end{array}$ \\
\hline 1 & America & 687.585 & 3.09 & 2225.19 \\
2 & Russia & 604.751 & 1.42 & 4258.81 \\
3 & Iran & 166.553 & 0.74 & 2250.72 \\
4 & Qatar & 158.509 & 0.05 & 31701.80 \\
5 & Canada & 154.829 & 0.34 & 4553.79 \\
6 & China & 117.05 & 13.38 & 87.48 \\
7 & Norway & 108.746 & 0.02 & 54373.00 \\
8 & Saudi Arabia & 103.01 & 2.4 & 429.21 \\
9 & Algeria & 78.6 & 0.27 & 2911.11 \\
10 & Indonesia & 70.402 & 0.35 & 2011.49 \\
& World & 3369.886 & 68.95 & 488.74 \\
\hline
\end{tabular}

\section{The consumption of natural gas in China}

As shown in Figure 2, from 1978 to 2014, China's natural gas consumption showed the trend of increase, and that of the average growth rate was 7.4\%. With China's economy quick development, from 2000 to 2014, China's natural gas consumption grows rapidly, and average growth rate was $11.5 \%$. There is no doubt that China's natural gas consumption will continue expanding in the future. In 2013, China's total natural gas consumption was 285.261 billion cubic meters, and accounted for $4.8 \%$ of the total world consumption, ranked the fourth in the world. In 2014, China's apparent consumption was 181.6 billion cubic meters, was year-on-year growth 7.4\%.

Natural gas accounts for a lower proportion in primary energy consumption structure. Since 2005, China's natural gas consumption has had a substantial increase. But at present, the proportion of natural gas in China's energy consumption structure is still low. According to BP Statistics, China's natural gas accounted for $5.1 \%$ in the proportion of primary energy consumption in 2013, which was far below $23.7 \%$ of the world average level.

The use of urban gas and gas power generation is relatively low, and ratio of industrial fuel and natural gas chemical industry is high in China. China's natural gas utilization mainly includes city gas, industrial fuel, natural gas power generation and natural gas chemical industry. But the natural gas consumption structure is not reasonable, industrial use is obviously high. In order to optimize natural gas usage structure, promote energy saving and emission reduction, in August 2007, China's government promulgated the 'Natural Gas Utilization Policy'. This ensured priority for city gas. With the improvement of environmental requirements and the living standard of people, there is a growing demand for city gas, and the natural gas consumption structure is optimized. The ratio of city gas in natural gas consumption increases gradually. It forms a relatively balanced consumption structure. In October 2012, National Development and Reform Commission issued again the 'Natural Gas Utilization Policy (2012)' to encourage the development of natural gas, increase the proportion of natural gas in primary energy consumption structure. These measures will further improve the proportion of city gas and natural gas power generation. Natural gas power generation will be developed rapidly in the future ${ }^{[2]}$. 


\section{The status of the import and export of natural gas in China}

Before 2007, China's natural gas exports are more than its imports, but after 2007, China became a net import country. Soon afterwards natural gas imports increased sharply. In 2014, the foreign-trade dependence of natural gas is 32.2\%. China's natural gas imports began to slow down in 2014 . According to Chinese customs statistics, the total imports of natural gas are $567 \times 10^{8} \mathrm{~m}^{3}$ in 2014 , increases $44 \times 10^{8} \mathrm{~m}^{3}$ compared last year. Among them, the LNG' imports is $295.68 \times 10^{8} \mathrm{~m}^{3}$ and increase $17.5 \%$, which is the main driving force of the total import growth. Imports of natural gas change with the season fluctuation in China. In winter, due to heating demand increase, imports of natural gas grow rapidly. For example, in 2014, natural gas imports of July accounts for only $40.9 \%$ that of December.

\section{The problems of China's natural gas development}

Chinese government enacted 'Energy Development Strategic Action Plan (2014-2020)'. That is, by 2020, China's total primary energy consumption will be controlled within 4.8 billion tons of standard coal. Natural gas consumption will reach $10 \%$ of total energy consumption and amount to 360 billion cubic meters. Besides, domestic conventional natural gas, shale gas and coal bed methane aggregate aim for 245 billion cubic meters, natural gas external dependence is less than 32\%. However, in 2014, China's natural gas production is 132.9 billion cubic meters, and China's natural gas apparent consumption is 181.6 billion cubic meters. So China needs to import large volumes of natural gas. Because of the instability of natural gas in the international market, there are severe challenges in developing nature gas in China. Therefore, based on the current situation, there are the following problems about the development of China's natural gas.

The gap between the supply and demand of natural gas is increasing year by year. Since 2000, average annual growth rate of China's natural gas production is $11.9 \%$. At the same time, average annual growth rate of China's natural gas consumption is $15.6 \%$. The gap is $3.7 \%$. The growth rate of production doesn't keep up with the growth rate of consumption. Before 2008, the supply and demand of nature gas kept balance generally. But the gap between supply and demand has been shown since 2009. However, in 2014, China's natural gas imports reached 56.7 billion cubic meters, and the external dependence of China's natural gas is 32.4\%. Compared to 2013, the external dependence increased $1.2 \%$. With the development of low carbon economy, clean and low-carbon natural gas will be developed quickly, and the gap between its supply and demand will further largen. According to the prediction of the International Energy Agency, until 2035, China's natural gas consumption will reach 634 billion cubic meters; and at the same period that of the domestic production is only 303 billion cubic meters, the gap of supply and demand will reach 331 billion cubic meters in China. The gap is a threat to China's energy security and also affects the sustainable development of economy in China.

Pipeline facilities are relatively backward. Although the natural gas infrastructure construction has made great achievements in the past ten years, China's natural gas industry base is still weak compared with developed countries. Main natural gas networks are not yet perfect in China. There are the mismatch problems of the pipeline construction and the supply and demand of natural gas in most of the areas. Because china's natural gas resources are away from its consumer market, many areas still lack the support of the gas transmission pipeline network, and affect the development of downstream consumer markets. The further exploration and development of China's natural gas is restricted. In addition, storage infrastructure construction of China's natural gas lags behind, and there are difficulties in natural gas peak shaving. Although, in 2014, the built pipelines were 83 thousand $\mathrm{km}$, and new increased pipelines were $5013 \mathrm{~km}$ than last year. But, it still doesn't meet the domestic needs. Pipeline construction is a long-term behavior, it doesn't solve fully in the short term. Therefore, the contradiction between rapid increase of natural gas demand and infrastructure backwardness will affect the development of China's natural gas. 
Unreasonable pricing mechanism. For a long time, the price of China's natural gas was enacted by government. In recent years, China introduced market competition mechanism, but it did not form a sound market system. In the pricing of natural gas, there were two sides problems, the one is china's natural gas prices did not reflect the relationship between supply and demand, the another one is the prices can not represent true value of natural gas.

Natural gas prices did not reflect the market relationship between supply and demand. The long-term monopoly of price by government has brought advantages for development in nature gas industry, but insufficient competition causes lack of technological innovation and the impetus of cost reduction. The government supervises strictly natural gas pricing, but there are the bulls management and lack of unified coordination. The Government doesn't monitor effectively and understand the needs of the actual production of the enterprises. Besides, it causes the failure of supervision and pricing due to the lag of cognition the market supply and demand. Although in recent years the government allow natural gas's prices to have a certain floating, price control is still tight. And with the rise of natural gas imports, the Chinese government will have to give massive subsidies to solve the price gap caused by transportation and sales of natural gas. At the same time, the rigid price of natural gas separates natural gas from alternative energy and leads to the unreasonable consumption structure. And the lower natural gas price is not conducive to the saving utilization of natural gas. The original pricing mechanism plays an important role in the development of natural gas industry under the condition of planned economy. But with the rapid development of China's natural gas industry, the original pricing mechanism has not already fitted the needs of new situation. The price of natural gas does not reflect timely the actual market supply and demand and does not encourage enterprises production and guide consumption.

The price structure of natural gas is not reasonable. China's urban natural gas prices including factory price, pipeline transportation price and urban pipeline network price. At present, the price of natural gas is still relatively low because of the differences of load distance and economic situation. Cost-plus pricing method is mainly used in which there is large scale natural gas storage volume nearby consumption areas. And it does not agree with the current situation that China's natural gas resources are far away from the eastern developed areas. From the view of China's natural gas prices structure, the proportion of urban pipeline network cost in the end-user's natural gas sales price is too high. In other developed countries of the world, natural gas prices using in the industry and commerce are generally lower than that of residents using. That of prices ratio of the European Union and the OECD countries is about 1:2, that of the United States and the Netherlands is about 1:2.5. But China's industrial and commercial gas prices are above the residents'. There is also a problem in the pricing of imported gas and domestic gas. The cost is different according to different sources of natural gas. In the pricing of natural gas, it is not fair to use the weighted average method to make uniform price setting. The pricing mechanism which do not connect with the market is difficult to ensure that the interests coordination of all parties. Due to the difference in resource endowments, the natural gas production cost is different in different areas. In addition, transportation cost of pipeline is also different. It is general phenomenon that there is natural gas from different producing areas in the supply of China's natural gas in many cities. This causes many kinds of natural gas prices in the same city. ${ }^{[3]}$ Diversification of natural gas sources leads to the coexistence of multiple prices, and putting pressure on natural gas pricing.

\section{Countermeasures and suggestions}

Guiding actively the market demand of natural gas. On one hand, government should accelerates the development of power generation of natural gas, mobilize the enthusiasm of gas production enterprises, power generation enterprises and power grid enterprises, and promote the development of gas power generation scale by enacting gas-electric development overall planning, deepening the reform of the gas price, and subsidies means and so on. On the other hand, government should expand the utilizing domain of industrial gas by improving utilizing efficiency of industrial gas and guaranteeing economical efficiency of industrial gas. Besides, government should exploit 
continuously natural gas transportation market through related technical standards, and prioritize the development of LNG heavy trucks, LNG power driving ship, LNG bus and CNG passenger car.

Increasing the diversification degree of natural gas supply. Diversification is the basic condition for ensuring the safety of natural gas supply. The more sources of supply are, the smaller the proportion of the interruption is. China demands to establish a domestic gas supply branch pipeline, main trunk networking, form gas pipe basic network from west-east to the north-south of China, and ensure the supply of foreign natural gas. On one hand, we should improve the diversification of natural gas imports. We should negotiate with related resource rich countries in natural gas pipeline, and sign the supplemental agreements to ensure the project resource supply and the safe operation of pipelines. On the other hand, we should make great efforts to improve the domestic gas supply capacity, develop the domestic shale gas, tight gas and coal-bed gas, and optimize continuously the production technology of coal-bed gas.

Improving the construction of natural gas infrastructure and promoting the operation capability of the pipeline. We should speed up the construction of natural gas pipeline and develop the pipeline operation platform. With the development and utilization of natural gas, natural gas pipeline and other infrastructure still can't meet the needs of the market, which becomes a restriction of the industry development. We should try our best to construct pipeline and gas storage, formulate relevant policies to accelerate the whole industry chain construction, especially focus on large-scale gas storage which plays an important role in the course of the winter peaking shaving. Governments at all levels should give preferential treat in the sales price, the supporting project, land and other basic conditions, and encourage state-owned and private capitals to participate competitions in order to completely solve the problem of load pressure.

Deepening the reform of natural gas prices. Pricing reflects the relationship between supply and demand of natural gas market. Establishing a competitive market is the ultimate goal of China's natural gas pricing mechanism. Marketing is the trend of China's natural gas price reform, The market pricing can promote the development of natural gas market and configure reasonably and efficiently the natural gas resources. We should rationalize the price of import gas and domestic gas. With the increase of China's natural gas imports in the future, China should distinguish pricing between domestic gas and import gas.

\section{Acknowledgements}

This work was financially supported by The Beijing social science fund project (SZ201510017010), BIPT-BPOAL-2014 and URT Project (2015J00032).

\section{References}

[1] Jialiang and Lu, Suping zhao: On the Structural Adjustment Energy Consumption and Natural Gas Industry Development Prospect in China, Natural Gas Industry, Vol. 11 (2013), p. 10. In Chinese

[2] Zhishuang, Zhu: Historical Review and Latest Progress of China's Natural Gas Market Development, China Market, Vol. 8 (2015), p. 45-47. In Chinese

[3] Qianya, Wang: Domestic Natural Gas Pricing Mechanism Reform Research and Policy Suggestions, Prices Monthly, Vol. 2 (2015), p. 18-21. In Chinese 